\title{
UX Modeling: The Missing Parameters: The Need for Specificity
}

\author{
Fazillah Mohmad Kamal*1 ${ }^{1}$ Emmanuel O.C. Mkpojiogu' ${ }^{2}$ Azham Hussain ${ }^{3}$ \\ ${ }^{*}$ School of Quantitative Sciences, Universiti Utara Malaysia, 06010 UUM, Sintok, Malaysia, \\ fazillah@uum.edu.my \\ ${ }^{2}$ School of Computing, Universiti Utara Malaysia, 06010 UUM, Sintok, Malaysia; \\ Department of Computer and Information Technology, Veritas University, Abuja, Nigeria \\ ${ }^{3}$ School of Computing, Universiti Utara Malaysia, 06010 UUM, Sintok, Malaysia
}

\begin{abstract}
Modeling user experience (UX) is vital in properly understanding all its facets and to deconstruct user experience for the purpose of design, measurement and evaluation. A cursory examination of prior UX models indicates issues worthy of note. Sequel to this, this paper reveals the absence of the parameters of time and context of interaction in the modeling of previous models of user experience. The paper strongly advocates the inclusion of these components in all user experience models. The reason for these advocacy and recommendation is that UX is better understood when considered within a context of use as no two experiences are the same. Experience is typically unique and situated in a continuum (time and context). Moreover, the evolution of UX clearly speaks about the significance of time in the conceptualizing and making sense of experience. Hence, when developing UX models for the design or evaluation of experience, it is pertinent to include the time and context of use in such modeling.
\end{abstract}

Key words: Context of use, Time, Missing parameters, Specificity, UX models

\section{INTRODUCTION}

Extant literature reveals that several UX models exist. Jordan (2000) developed a model that comprised of functionality at the bottom, followed by usability (middle) and pleasure at the top. According to Jordan (2000), pragmatic and instrumental needs are very fundamental and foundational to user experience. As these needs are met, users' needs for pleasure and fun (hedonic needs) then come as higher order needs. Moreover, Vilnai- Yavetz and Rafaeli (2005) maintained that three dimensions are correlated with the appreciation of any object, namely instrumentality (usability and usefulness), aesthetics (sensual experience), and symbolism (meaning of products). Also, a pyramid is visualised by Markowitz's model, built from Maslow's hierarchy of needs. The 'strong' parameters of the product in terms of functionality and functions are located at the bottom of Markowitz's pyramid. There is a change to 'softer' metrics in the context of customer interface, thoughts, and broader meaning at the peak, going upwards. Wright et al. (2003) categorized UX into four threads to explain experiences and six processes of making sense of an experience. The four threads comprise, inter alia: i) the sensual, ii) the emotional, iii) the spatio-temporal, and iv) the compositional thread. Wright et al.'s (2006) provided a contextual approach where the whole experience is situated in a place and time and encompass both visceral and emotional 'felt' sensations (Wright, Wallace, \& McCarthy, 2008). The six processes of sense-making assist in describing how an individual subjectively makes sense of an experience. They comprise anticipating, connecting, interpreting, reflecting, appropriating, and recounting (McCarthy \& Wright, 2004). The four threads of experiences suggested assist to explain the constituents of an experience with reference to feelings, emotions, context or space, and time, along with the interaction between the components of an experience. The six processes of sense-making assist to mirror on individual sense-making of an experience (Kraus, 2017). McCarthy and Wright's categorization model was however not hierarchical.

In addition, Hancock et al.'s (2005) and Joarderet,. al. (2015) model consist a hierarchy of five qualities. From the basement is security, functionality, usability, pleasure and at the very top is individuation. Their model breaks UX needs into two: ergonomic and hedonomic needs. In addition, Mahlke graded elements of UX output into 'instrumental' and 'non-instrumental' values (Mahlke, 2008). The discrepancy between the two distinct traits dates back to Hassenzahl (2002), who called them 'pragmatic' and 'hedonic'Thuring and Mahlke (2007) grouped UX components into the perception of instrumental attributes (controllability, efficacy, learning, etc.), emotional reactions (feelings, motor gestures, physiological reactions), and non-instrumental attributes (visual aesthetics, affectivity, recognition, etc.) perception (Minge \& Thuring, 2018). In addition, the paradigm of Hassenzahl (2003) breaks down UX consistency characteristics into qualities that are pragmatic and hedonic. Pragmatic qualities contribute to programme accessibility, utility and reliability (e.g. simple, supportive, useful and controllable) (that is, do-goals of a user). On the other hand, hedonic qualities concern the expression of personality, the provoking of memories, and the supply of stimulation (e.g., 
excellent, outstanding, thrilling, and interesting). These qualities stress the social well-being of people (that is, the goals of users). The interpretation of these traits by an end customer contributes to an interpretation of the attractiveness of the product (e.g., "It's good / bad "), subjective effects (e.g., enjoyment, satisfaction) and behavioural effects (e.g., increased time spent with the product). Although pragmatic characteristics are concerned with the accomplishment of dogoals, hedonic characteristics are concerned with meeting begoals (Hassenzahl, 2003). Do-goals are the particular result that the end user aims to attain, whereas be-goals are based on basic human needs. Hassenzahl (2010) stresses four features of UX to have a deeper interpretation of UX: contextual, holistic, complex, and context-dependent. All software systems have any UX, positive or not, whether or not the UX has been expressly taken into consideration during development. Analysis has shown that the possibility of producing a desirable UX can be improved by such activities (Hassenzahl, 2010; Mkpojiogu et al., 2018).

Table 1: UX Models

\begin{tabular}{|l|l|}
\hline Author(s) & UX Models \\
\hline Tractinsky (1997) & Classical \& Expressive aesthetics \\
\hline Jordan (2000) & Functionality, Usability, \& Pleasure \\
\hline $\begin{array}{l}\text { Vilnai-Yavetz \& } \\
\text { Rafaeli (2005) }\end{array}$ & $\begin{array}{l}\text { Instrumentality, Aesthetics, \& } \\
\text { Symbolism }\end{array}$ \\
\hline $\begin{array}{l}\text { Tractinsky \& Zmiri } \\
(2006)\end{array}$ & Usability, Aesthetics \& Symbolism \\
\hline $\begin{array}{l}\text { Hassenzahl (2003, } \\
\text { 2004) }\end{array}$ & Pragmatic \& Hedonic \\
\hline $\begin{array}{l}\text { Wright et al. (2003, } \\
\text { 2008) }\end{array}$ & $\begin{array}{l}\text { Sensual, Emotional, Spatio-temporal, } \\
\text { \& Compositional }\end{array}$ \\
\hline $\begin{array}{l}\text { Hancock et al.,, } \\
(2005)\end{array}$ & $\begin{array}{l}\text { Security, Functionality, Usability, } \\
\text { Pleasure, \& Individuation }\end{array}$ \\
\hline $\begin{array}{l}\text { Thuring \& Mahlke } \\
(2007)\end{array}$ & $\begin{array}{l}\text { Instrumental, Non-instrumental \& } \\
\text { Emotional }\end{array}$ \\
\hline Mahlke (2008) & Instrumental \& Non-instrumental \\
\hline $\begin{array}{l}\text { Buccini \& Padovani } \\
\text { (2007); Olsson } \\
\text { (2012) }\end{array}$ & $\begin{array}{l}\text { Instrumental, Cognitive \& Epistemic, } \\
\text { Emotional, Sensory, Social, } \\
\text { Motivational \& Behavioral, }\end{array}$ \\
\hline Park et al. (2015) & Utilitarian, Sociability\& Affective \\
\hline
\end{tabular}

Table 1 shows prior studies indicating UX models. Tractinsky (1997) was one of the earliest studies on UX modeling that broke down UX into measurable dimensions. Jordan (2000) classified UX into functionality, usability and pleasure. Vilnai-Yavetz and Rafaeli (2005) broke down UX into instrumentality, aesthetics and symbolism. The thesis of Rafael and Vilnai-Yavetz (2004) was used by Tractinsky and Zmiri (2006) to suggest three distinct qualities of product quality: accessibility, aesthetics and symbolism. To better account for the cognitive and social dimensions of product use, Forlizzi expanded this model. Hassenzahal (2003, 2004) modeled UX into two dimensions, namely: pragmatic and hedonic, he made a distinction between two perceptions of quality: pragmatic and hedonic. Pragmatic consistency refers to the potential of the product to promote the attainment of behavioural objectives (i.e. performance, efficiency, reliability-in-use, utility and ease-of-use). In the other side, hedonic quality applies to the self or being of the user. It refers to stimulus, i.e. the ability of the product to stimulate and allow personal development, and identity, i.e. the ability of the product to resolve the desire to convey oneself by items that one owns. Hassenzahl (2004) introduced two independent overall evaluative judgments: elegance and goodness, on the nature of digital goods. He discovered that goodness is mainly motivated by functional factors (that is, utility and usability) (Hussain et al., 2019a; 2019b). He considered attractiveness, however, to be a reasonably social feature, primarily influenced by identity (that is, the ability of the product to meet the needs of self-expression). Moreover, Mahlke's (2006) expressive aesthetics compares to Hassenzahl's (2004) stimulation and beauty.

Mahlke (2008) viewed UX as consisting of instrumental and non-instrumental dimensions. Olsson (2012) In a more recent work described and classified UX based on the typology by Buccini and Padovani (2007) with some slight condensation and refinement. The identified classifications of UX were categorized further into six categories that signify UX, namely: cognitive and epistemic experiences, instrumental experiences, sensory experiences, emotional experiences, social experiences, and motivational experiences. Recently, Park (2015) unpacked UX as consisting of utilitarian, affective and sociability dimensions. The above studies did not reflect the holistic nature of UX as none of the studies included the totality of the dimensions of UX. A literature review revealed that there are more dimensions that make up UX (such as, interactivity, affectivity, engageability, ludicity, etc.). These dimensions were not studied collectively in any single study. Furthermore, literature review also revealed the different attributes that are associated with the discovered dimensions (Hussain et al., 2018; (Mkpojiogu et al., 2019).

However, one defect of these models is the absence or omission of specificity. The models were generic as context and time were not included in the modeling. The noninclusion of context and time in the modeling makes the understanding and sense making of user experience challenging. Interaction takes place within a specific context which defines the uniqueness of the users' experience with such products. Also, time is important in experience as experience is known to fluctuate and evolve with time. Experience is dynamic and any meaningful model that measures user experience must include the concept of time. On this note, this paper advocates for the contextualization and timeliness of user experience and the inclusion of these in the modeling of user experience.

\section{METHODOLOGY}

The study employs literature analysis strategy in understanding prior studies on the modeling of user experience. Past models on UX were examined to discover their structure. The protocol for this study include: i) Downloading of relevant articles on UX modeling, ii) Critically analyzing the downloaded articles, iii) Observing pertinent gaps in the models, iv) Underscoring the need of 
time and context of use, and v) Recommending the inclusion of time and context of use in UX models. Figure illustrates the research methodology for this study.

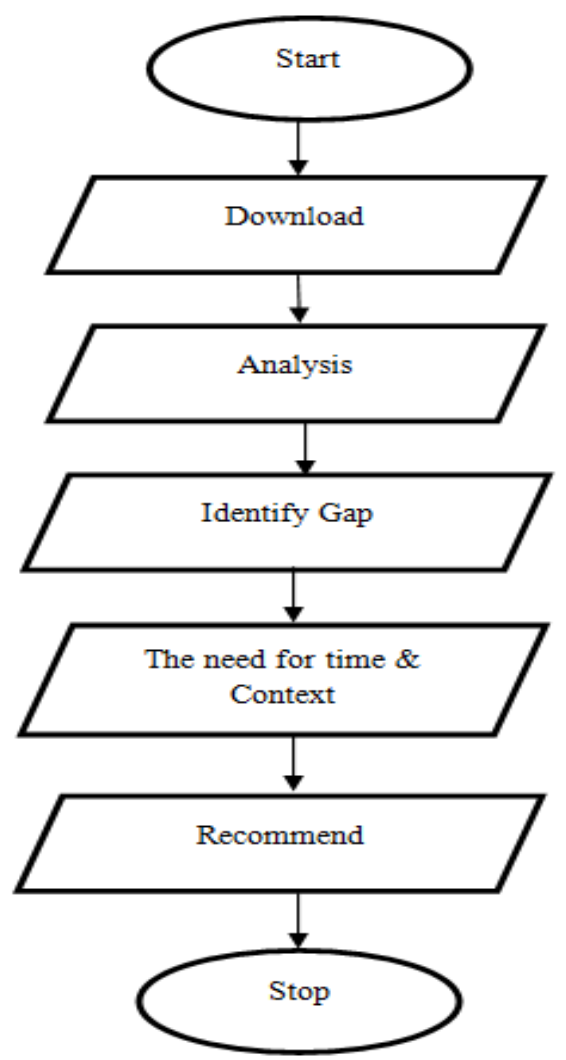

Figure 1: Research Methodology

\section{RESULTS}

The results of the study reveal that previous user experience models focused on dimensioning experience into quality facets that contribute to user experience. One obvious observation was the omission of time and context of use (interaction) in the various models. The papers advocates and recommends the inclusion in every UX model, the concept of time and context of interaction. The recommended framework for such models will be as in Figure 2.

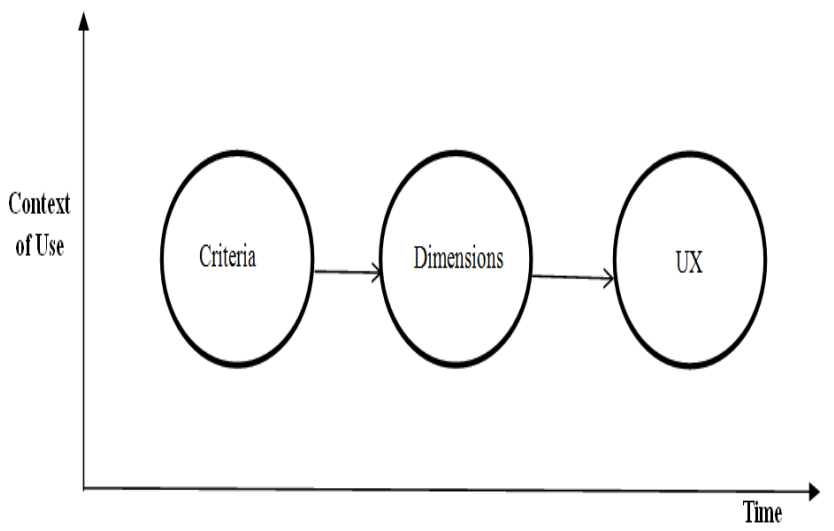

\section{CONCLUSION}

In sum, the paper uncovers the non-inclusion of the components of time and context of use in the modeling of prior models of UX. The paper strongly advocates the inclusion of these parameters in all user experience models. The reason for these advocacy and recommendation is that UX is better understood when considered within a context of use as no two products' UXs are the same. Experience generally is unique and it is situated in time and space. Further, the temporality and dynamism of UX explains the importance of time in the understanding of UX. Therefore, when modeling UX for either design or evaluation purposes, context on use and the time of such use must be crucially taken into consideration.

\section{REFERENCE}

[1] Buccini, M. \& Padovani, S. (2007). Typology of experiences. Proceedings of DPPI'07. ACM Press, pp. 495-504.

[2] Hancock, P.A., Pepe, A., \& Murphy, L.L. (2005). The power of positive and pleasurable ergonomics.

[3] Hassenzahl, M. (2003). The thing and I: understanding the relationship between user and product. In Blythe, M., Monk, A.F., Overbeeke, K., Wright, P. (eds.), Funology: from usability to enjoyment, (pp. 31-42), Kluwer.

[4] Hassenzahl, M. (2004). The interplay of beauty, goodness, and usability in interactive products. Human-Comp. Interaction, 19(4), 319-349.

[5] Hassenzahl, M. (2010). Experience design: technology for all the right reasons. Synthesis Lectures on Human-Centered Informatics, 3(1), 1-95.

[6] Hussain, A., Mkpojiogu, E.O.C. \& Hassan, F. (2018). Dimensions and sub-dimensions for the evaluation of $\mathrm{m}$ learning apps for children: A review. International Journal of Engineering \& Technology (IJET), 7 (3.20), 291-295.

[7] Hussain, A., Mkpojiogu, E.O.C. \& Kutar, M. (2019a). The impact of software features' perceived importance on the perceived performance of software products' quality elements. Journal of Computational and Theoretical Nanoscience. 16 (5-6), 2135-2140.

[8] Hussain, A., Shamala, P., \& Mkpojiogu, E.O.C. (2019b). The effect of software features' perceived importance on the observed performance of software product qualities. Journal of Advanced Research in Dynamical and Control Systems (JARDCS), 11(08-SI), 1076-1082.

[9] Jordan, P. W. (2000). Designing pleasurable products: An introduction to the new human factors. Taylor \& Francis.

[10] Joarder, M.H.R., Subhan, M., Ghani, A.B.A., Islam, R. (2015). Pay, security, support and intention to quit relationship among academics in developing economy. Investment Management and Financial Innovations, 12 (3), pp. 190-199.

Figure 2: A UX Modeling Framework 
[11] Kraus, L. (2017). User experience with mobile security and privacy mechanisms. Doctoral Dissertation, Technischen Universitat Berlin.

[12] Mahlke, S. (2008). User experience of interaction with technical systems: theories, methods, empirical results, and their application to the development of interactive systems. Doctoral dissertation, Belin: Berlin University of Technology.

[13] McCarthy, J., \& Wright, P. (2004). Technology as experience. Interactions, 11(5), 42-43.

[14] Minge, M. \& Thuring, M. (2018). Hedonic and pragmatic halo effects at early stages of user experience. International Journal of Human-Computer Studies, 109, 13-25.

[15] Mkpojiogu, E.O.C., Hashim, N.L., Hussain, A., \& Tan, K.L. (2019). The impact of user demographics on the perceived satisfaction and comfort of use of m-banking apps. International Journal of Innovative Technology and Exploring Engineering, 8(8S), 460-466.

[16] Mkpojiogu, E.O.C., Hussain, A., \& Hassan, F. (2018). A systematic review of usability quality attributes for the evaluation of mobile learning applications for children. ICAST 2018, AIP Conf. Proc. 2016, https://doi.org/10.1063/1.5055494

[17] Olsson, T. (2012). User expectations and experiences of mobile augmented reality services. Tampere University of Technology, Tampere.

[18] Park, J., Han, S.H., Lee, M., \& Jang, H. (2015). A literature survey on UX design properties and principles of smart device design for the disabled.

[19] Thüring, M. \& Mahlke, S. (2007). Usability, aesthetics, and emotions in human-technology- interaction. International Journal of Psychology, 42, 253-264.

[20] Tractinsky, N. (1997). Aesthetics and apparent usability: empirically assessing cultural and methodological issues. In Proceedings of the ACM SIGCHI Conference on Human factors in computing systems (pp. 115-122). ACM.

[21] Tractinsky, N., \& Zmiri, D. (2006). Exploring attributes of skins as potential antecedents of emotion in HCI. In Aesthetic computing (pp. 405-422).

[22] Vilnai-Yavetz, I., \& Rafaeli, A. (2005). Instrumentality, aesthetics, and symbolism of office design. Environment and Behavior, 37(4), 533-551.

[23] Wright, P., Blythe, M., \& McCarthy, J. (2006). User experience and the idea ofdesign in HCI. In Interactive Systems. Design, Specification, and Verification(pp. 114). Springer Berlin Heidelberg.

[24] Wright, P., McCarthy, J., \& Meekison, L. (2003). Making sense of experience.” In: Funology. ～(pp.4353), Springer.

[25] Wright, P., Wallace, J., McCarthy, J. (2008). Aesthetics and experience-centered design. Transactions on Computer-Human Interaction, 15(4), 21. 